\title{
Linguistic Predictors of Post-Traumatic Stress Disorder Symptoms Following 11 September $2001^{\dagger}$
}

\author{
WENDY D'ANDREA ${ }^{1 *}$, PEARL H. CHIU ${ }^{2,3}$, BROOKS R. CASAS ${ }^{2,3 *}$ and PATRICIA DELDIN ${ }^{2,4}$ \\ ${ }^{1}$ Department of Psychology, The New School, New York, USA \\ ${ }^{2}$ Department of Psychology, Harvard University, Cambridge, USA \\ ${ }^{3}$ Virginia Tech Department of Psychology, and Salem VA Medical Center, Virginia Tech Carilion Research Institute, Roanoke, USA \\ ${ }^{4}$ Department of Psychology, University of Michigan, Ann Arbor, USA
}

\begin{abstract}
Summary: Prior research has linked content analysis drawn from text narratives to psychopathology in trauma survivors. This study used a longitudinal design to determine whether linguistic elements of narrative memories of first hearing about the events of 11 September 2001 predict later post-traumatic stress disorder (PTSD). Narratives and self-report PTSD symptoms were collected within 1 week and again 5 months after 9/11 in 40 undergraduates. People who used more "we" words at Time 1 had fewer acute PTSD symptoms. Use of more cognitive mechanism words, more religion words, more first-person singular pronouns, and fewer anxiety words at Time 1 were related to more chronic PTSD symptoms. Linguistic characteristics accounted for variance in chronic PTSD symptoms above and beyond acute PTSD symptoms. This study provides evidence that lasting PTSD symptoms can be predicted through language in the immediate aftermath of the trauma. Copyright () 2011 John Wiley \& Sons, Ltd.
\end{abstract}

The United States was indisputably changed in the aftermath of the events of 11 September 2001. However, some people experienced significant and long-lasting distress above and beyond that of the average citizen. Although events that typically lead to post-traumatic stress disorder (PTSD) symptoms include combat, physical and sexual assault, and life-threatening accidents, PTSD can also occur in response to national disasters, if one perceives one's own life to be in danger. Indeed, studies have indicated that the general population experienced increased PTSD symptoms in the weeks and months following 9/11. Schuster, Stein, and Jaycox (2001) found that $90 \%$ of a random sample of 560 adults had at least one symptom of PTSD in the immediate aftermath of 9/11. Similarly, Cardenas, Williams, and Wilson (2003) found elevated levels of PTSD symptoms in college students following 9/11. Blanchard, Rowell and Kuhn (2005) found an increase in PTSD symptoms in college students immediately following 9/11, and a continued increase in PTSD symptoms 1 year later. This study examines the relationship between personal narratives and symptoms of traumatic stress reported by a cohort of undergraduates in the weeks and months following $9 / 11$.

As described by Pennebaker, linguistic elements refer to both the form and content of text (Pennebaker, Francis, \& Boothe, 2001). Form is exemplified by articles, prepositions, negations and assents, verb tense, pronouns, and structure of text. Content is exemplified by the nouns, verbs, and descriptive elements, such as words related to emotion, sensation, thought, and action. Generally speaking, first-person singular pronouns tend to correlate positively with psychological distress, such as depression (Rude, Gortner, \& Pennebaker, 2004; Wolf, Sedway, Bulik, \& Kordy, 2007), and negatively

*Correspondence to: Wendy D'Andrea, PhD, Assistant Professor, Department of Psychology, 7th Floor, The New School, New York, NY, 10011, USA. E-mail: dandreaw@newschool.edu

These data were collected in the Department of Psychology, Harvard University, Cambridge MA 02138.

These authors contributed equally to this project. with social dominance (Gonzales, Hancock, \& Pennebaker, 2010). In contrast, second-person pronouns may reflect community (Simmons, Gordon, \& Chambliss, 2005), or social dominance (Pennebaker \& Lay, 2002; Sexton \& Helmreich, 2000). Verb tense may communicate one's focus on an event; for example, Tausczik and Pennebaker (2010) suggest that use of present tense when describing past events may indicate that feelings are unresolved about the event. Similarly, use of words reflective of cognitive mechanisms (e.g. think, believe) tend to reflect attempts to appraise or make meaning of events. Other studies have suggested that the use of causal words increases during upsetting events (Boals \& Klein, 2005), which correlates with alleviation of distress, perhaps because people are attempting to understand and resolve the event (Kross \& Ayduk, 2008). Linguistic elements of narrative recollections of individuals who have experienced trauma have previously been shown to be sensitive to traumatic stress.

For example, in the weeks following a traumatic event, people tend to switch to using more first-person plural than first-person singular pronouns, indicating a tendency towards adaptive social bonding (e.g. Chung \& Pennebaker, 2007; Stone $\&$ Pennebaker, 2002). Use of more negative emotion words, cognition words, and insight words predict health improvements in college students when writing about traumatic events (Pennebaker, Francis, \& Boothe, 2001). Even when controlling for assault-related characteristics, the presence of words related to death and dying predict treatment resistance for people in therapy for PTSD (Alvarez-Conrad, Zoellner, \& Foa, 2001).

Studies of the linguistic components indicate that the narratives of the general population were impacted by the events of $9 / 11$. One group analyzed the online journals of over 1000 participants before and after 9/11, by downloading entries made in a publicly-available internet forum (Cohn, Mehl, \& Pennebaker, 2004). Writing samples were downloaded at two time points: immediately after the attacks, and again 6 weeks later. They found that use of negative emotion words and more abstract and impersonal words increased after the attacks. In the 6 weeks following 9/11, negative emotion words returned to baseline levels, social referencing words 
dropped below baseline levels, and abstract words remained elevated compared with baseline levels. While these data present interesting insights into how a general sample may process information in the aftermath of disaster, the relationship between such linguistic elements and trauma-related pathology is not addressed. Similarly, Lee and Park (2004) examined two writing samples from 36 college students immediately after 9/11, and again 2 months later. Participants were asked to write about their reactions to the event, as well as to write their understanding of why the attacks occurred. Their sample utilized more words overall and more words related to religion, family and home immediately following 9/11 (Lee \& Park, 2004), which the authors suggest reflect needs for security and community.

However, only one investigation has examined how language usage correlated with psychological reactions. Fivush, Edwards, and Mennuti-Wasbhurn (2003) examined how narrative elements were related to feeling shocked or emotionally distressed upon hearing about the attacks. When asked about their recollections of how distressed they felt upon hearing about the attacks, 1 and 6 months after the attacks, people who utilized more cognitive processing words and negative emotion words immediately following 9/11 reported less distress. However, that study did not examine ongoing distress or psychiatric symptoms, but rather measured distress felt at the time of the event as well as one's recollection of distress. Taken together, these data highlight that traumarelated writing tasks may elicit evidence of higher or lower social bonding, information processing, and emotional distress, which may in turn predict higher or lower psychological distress. Key findings appear to be related to pronouns and cognitive or social processes.

According to Tausczik and Pennebaker (2010), "The words we use in daily life reflect what we are paying attention to, what we are thinking about, what we are trying to avoid, how we are feeling, and how we are organizing and analyzing our worlds" (p. 30). However, in the case of post-traumatic reactions, affected persons may not be in a position to directly report upon their distress. Symptoms of Acute Stress Disorder and PTSD include both avoidance and numbing, which could lead to an under-reporting of distress. In order to examine early cognitive factors related to the development of post-traumatic stress syndromes, researchers may find that relying upon "objective" assessments provides data that complements or enhances self-report. Therefore, linguistic elements of narrative texts may (i) play a critical role in understanding the cognitive changes associated with trauma and (ii) carry potential utility for predicting long-lasting PTSD symptoms. To this end, we examined PTSD symptoms in relation to narratives written immediately following 9/11, and again 5 months later. The narratives were implemented as prospective measures of post-traumatic stress that do not rely upon self-report scales. These data will extend previous literature by comparing the predictive ability (though not necessarily causal) of linguistic variables versus self-report with respect to later PTSD symptoms. Furthermore, these data will provide insight into the linguistic features of post-traumatic responses in the immediate aftermath of a potentially traumatic event.

Given the data reviewed above, we expected that the participants whose early narratives feature little evidence of social processes would have higher sustained post-traumatic stress symptoms. In accord with Tausczik and Pennebaker's (2010) and Fivush et al.'s, (2003) observations about cognitive distancing as predictive of distress, we predicted that use of cognitive mechanism words would relate to distress. Similarly, given that early emotional numbing predicts later PTSD symptoms (Ozer, Best, Lipsey, \& Weiss, 2003), we predicted that use of fewer emotional words in early narratives, as indexed by anxiety and anger words, would relate to symptoms. Moreover, given that a PTSD diagnosis is related to life threat, we hypothesized that language related to death may be a significant indicator of early distress. Finally, as religious coping has been cited as both a risk factor and protective factor in traumatic stress and thus has an ambiguous position in the literature, we further examined the relation of religion words to distress. Religious coping has been cited as both a risk factor and protective factor in traumatic stress (Gerber, Bolls, \& Schuettler, 2011; Ano \& Vasconcelles, 2005).

In particular, we sought to answer the following questions:

1. What features of narratives written immediately following 9/11 are related to PTSD symptoms in the immediate aftermath?

2. How well do early PTSD symptoms predict sustained PTSD symptoms?

3. What features of narratives written immediately following 9/11 attacks predict PTSD symptoms in the following 5 months?

4. What features of narratives written 5 months after the attacks are related to PTSD assessed at that time?

5. Which predictors of chronic PTSD are strongest?

\section{METHOD}

\section{Participants}

The participants were recruited among undergraduate students who were given a battery of questionnaires within which the Impact of Events Scale-Revised (IES-R; Weiss \& Marmar, 1996) was embedded. ${ }^{1}$ All were college students, 18-20years of age. The participants were drawn from a university in the Boston area, and who may have had increased distress relative to much of the country because of the 9/11 flights, which originated from Boston Logan International airport. Individuals who indicated a direct connection to the events of 9/11 were excluded in order to minimize participant distress. This was the first week of the academic year, and the participants were recruited as part of a larger event for students interested in psychology studies. Forty students among those who completed the IES-R participated in the present study; 28 were re-assessed at Time 2. Seventeen of these participants were female. Because of the rapidity with which the study was assembled (in order to examine the participants in the immediate aftermath of 9/11), further participant details are not available.

\footnotetext{
${ }^{1}$ The larger study included a physiological assessment of reactivity to images related to $9 / 11$; data on depression symptoms were also collected but not analyzed here to minimize the likelihood of Type II errors.
} 


\section{Materials}

The IES-R (Weiss \& Marmar, 1996) is a 22-item questionnaire that assesses the intrusion, avoidance, and hyperarousal symptoms of PTSD. A score of 31 or above is considered diagnostically significant (Creamer, Mehl, \& Pennebaker, 2003). The IES-R was modified for the purpose of this study to reflect symptoms specifically related to the events of $9 / 11$ (e.g. "I avoid letting myself get upset when I think about the attacks").

\section{Procedure}

This study is part of a larger project on neurophysiological responses to affective stimuli and post-traumatic stress. Institutional Review Board approval was obtained. In the week immediately following 11 September 2001, individuals entering and exiting a student common area were given a series of surveys within which the IES-R was embedded. The participants who indicated they were not directly affected by the events of 9/11 were invited to the laboratory to complete the narrative task as part of a larger study examining emotional memories. For the narrative task reported here, the participants were given a lined sheet of paper with the instructions: "Please describe in as much detail as possible how you heard about the attack on Tuesday. Please include any particularly vivid details." No time limit was provided. These instructions were not intended to serve as a writing intervention. Other researchers have taken writing samples from publicly available texts, which have not used the prompts standard in interventions. Such studies have yielded valuable and interesting results (Cohn et al., 2004; Pennebaker \& Lay, 2002; Sexton \& Helmreich, 2000). Five to 6 months following 9/11 (i.e. February, March 2002), the participants were asked to return to the laboratory and re-assessed with the same narrative task and the IES-R (Time 2).

\section{Data analysis}

Linguistic analyses were conducted using the program Linguistic Inquiry and Word Count (Pennebaker, Francis, \& Booth, 2001), which computes words for categories such as "affective processes" (e.g. nervous, sad, angry), "cognitive processes" (e.g. cause, believe, know), and "pronouns" (e.g. I, we). Each category is computed as a ratio with respect to total word count.

The following categories were analyzed because of possible significance for this sample: Pronouns, Affective Processes (anxiety and anger, both of which are PTSD symptoms), Cognitive Processes, Social Processes (e.g. talk, hug), Death (e.g. dead, corpse), and Religion (e.g. God, pray). In order to more precisely understand the relationship of narratives to PTSD symptoms, we analyzed PTSD symptoms using both the IES summary scores and using the sub-categories of intrusion, avoidance, and hyperarousal symptoms.

We also analyzed results by gender, given that the reporting of emotional events and psychiatric symptoms may differ between men and women (Newman, Groom, Handelman, \& Pennebaker, in press).

\section{RESULTS}

\section{Narratives}

The participant narratives sometimes included details about what a participant was doing before the attacks, or what they did immediately afterward. The entire narrative was analyzed. Time 1 narratives were significantly longer, $t(36)=2.96, p<.01$. Time 1 narratives ranged from $28-339$ words $(M=138.18, S D=72.99)$; Time 2 narratives ranged from 17-236 words $(M=103.35, S D=51.25)$. Descriptive statistics for linguistic elements are listed in Table 1, as are rates of word usage from emotional writing paradigms. Standard rates are provided because some words, such as pronouns, are expected to be used with higher frequency than words from other categories, such as religion or death. Though tests of statistical significance were not possible, it appears that this sample used words related to anger and anxiety at a higher rate than other emotional writing samples, whereas they used first-person plural pronouns and words related to anxiety and cognitive mechanisms at a lower rate than other emotional writing samples. Rates of word usage are reported as proportions to total words in the narrative. Sample narratives can be seen in Appendix 1.

Table 1. Rates of word usage

\begin{tabular}{|c|c|c|c|c|c|}
\hline \multirow{2}{*}{$\begin{array}{l}\text { Linguistic } \\
\text { element }\end{array}$} & \multicolumn{3}{|c|}{ This study } & \multicolumn{2}{|c|}{$\begin{array}{c}\text { Across } \\
\text { emotional } \\
\text { writing } \\
\text { paradigms** }\end{array}$} \\
\hline & Minimum & Maximum & Mean & $S D$ & Mean \\
\hline \multicolumn{6}{|l|}{ Time 1} \\
\hline $\begin{array}{l}\text { First-person } \\
\text { singular }\end{array}$ & 0 & 18.75 & 9.96 & 3.47 & 10.40 \\
\hline $\begin{array}{l}\text { First-person } \\
\text { plural }\end{array}$ & 0 & 1.82 & 0.23 & 0.47 & 0.73 \\
\hline Anxiety & 0 & 1.63 & 0.25 & 0.48 & 0.68 \\
\hline Anger & 0 & 10.26 & 5.14 & 2.17 & 0.66 \\
\hline $\begin{array}{l}\text { Cognitive } \\
\text { mechanisms }\end{array}$ & 0 & 3.95 & 1.9 & 0.99 & 19.66 \\
\hline Religious & 0 & 7.02 & 1.37 & 1.32 & 0.17 \\
\hline Death & 0 & 2.63 & 0.28 & 0.58 & 0.18 \\
\hline \multicolumn{6}{|l|}{ Time 2} \\
\hline $\begin{array}{l}\text { First-person } \\
\text { singular }\end{array}$ & 0 & 19.5 & 11.17 & 3.12 & \\
\hline $\begin{array}{l}\text { First-person } \\
\text { plural }\end{array}$ & 0 & 2.35 & 0.22 & 0.55 & \\
\hline Anxiety & 0 & 1.14 & 0.04 & 0.2 & \\
\hline Anger & 0 & 10.34 & 4.79 & 2.31 & \\
\hline $\begin{array}{l}\text { Cognitive } \\
\text { mechanisms }\end{array}$ & s & 4.6 & 1.88 & 1.38 & \\
\hline Religious & 0 & 4.08 & 1.48 & 1.17 & \\
\hline Death & 0 & 2.04 & 0.17 & 0.47 & \\
\hline
\end{tabular}

**www.liwc.net/descriptiontable3.php. Based on 2931 writing samples from 29 studies "requiring participants to write about their emotions and thoughts about personally-relevant topics."

"Minimum" = minimum proportion of words of that type to total words used in any narrative; "maximum" = maximum proportion of words of that type to total words used in any narrative; "Mean" = mean proportion of words of that type to total words used in any narrative; " $S D$ " = standard deviation of proportion of words of that type to total words used in any narrative. 


\section{Attrition}

Severity of self-reported PTSD symptoms at Time 1 did not predict whether or not the participant returned for the Time 2 assessment.

\section{Post-traumatic stress disorder symptoms}

At Time 1, PTSD symptom levels had a mean score of 20.52 $(S D=10.60)$. Six participants reported a diagnostically significant IES-R score (Creamer et al., 2003). At follow up, PTSD symptom levels were lower $(M=14.38, S D=9.02)$. One participant reported continued symptoms considered diagnostically significant (Time 2 IES $=43$ ). PTSD symptoms decreased significantly over time, $t(28)=10.01, p<.05$.

What features of narratives written immediately following 9/11 are related to PTSD symptoms in the immediate aftermath? Bivariate correlations were used to determine the magnitude of the relationship between linguistic factors and PTSD symptoms immediately after 9/11 (Table 2). Higher overall PTSD symptoms, higher intrusion symptoms, and higher hyperarousal symptoms at Time 1 were significantly related to use of fewer first-person plural pronouns at Time 1 . No findings differed by gender.

How well do early PTSD symptoms predict sustained PTSD symptoms? (Table 3) To examine the relationship of acute PTSD symptoms to chronic PTSD symptoms, we conducted bivariate correlations. Time 1 PTSD symptoms were significantly correlated with Time 2 PTSD symptoms overall, and at the individual cluster level (e.g. Time 1 intrusion predicted Time 2 intrusion, etc.). When examined by gender, this effect was present in women $(r=.59, p=.01)$ and not in men $(r=.40, p=.22)$.

What features of narratives written immediately following 9/11 predict PTSD symptoms in the following 5 months? (Table 4.) Partial correlations were used to examine which narrative characteristics at Time 1 predicted psychopathology at Time 2, with PTSD symptom level at Time 1 as a covariate. Overall, more use of language indicative of anxiety at Time 1 predicted fewer Time 2 PTSD symptoms. In contrast, more use of language related to religion at Time 1 was related to

Table 2. Correlations between Time 1 linguistic elements and Time 1 PTSD symptoms

\begin{tabular}{|c|c|c|c|c|}
\hline $\begin{array}{l}\text { Linguistic } \\
\text { element }\end{array}$ & $\begin{array}{c}\text { Time } 1 \text { Total } \\
\text { PTSD } \\
\text { symptoms }\end{array}$ & $\begin{array}{c}\text { Time } 1 \\
\text { Intrusion } \\
\text { symptoms }\end{array}$ & $\begin{array}{c}\text { Time } 1 \\
\text { Avoidance } \\
\text { symptoms }\end{array}$ & $\begin{array}{c}\text { Time } 1 \\
\text { Hyperarousal } \\
\text { symptoms }\end{array}$ \\
\hline $\begin{array}{l}\text { T1 Word } \\
\text { count }\end{array}$ & .16 & .25 & -.10 & .31 \\
\hline $\begin{array}{l}\text { T1 First- } \\
\text { person } \\
\text { singular }\end{array}$ & .12 & .09 & .08 & .14 \\
\hline $\begin{array}{l}\text { T1 First- } \\
\text { person plural }\end{array}$ & $-.44 *$ & $-.39 *$ & -.31 & $-.41 *$ \\
\hline T1 Anxiety & -.2 & -.16 & -.11 & -.25 \\
\hline $\mathrm{T} 1$ anger & .04 & -.01 & -16 & -.10 \\
\hline $\begin{array}{l}\text { T1 Cognitive } \\
\text { mechanisms }\end{array}$ & .09 & .03 & .20 & -.03 \\
\hline T1 Religious & .05 & .10 & .07 & -.07 \\
\hline T1 Death & .19 & .23 & .17 & .04 \\
\hline
\end{tabular}

$* p<.05$,

Table 3. Correlations between Time 1 and Time 2 post-traumatic stress disorder symptoms

\begin{tabular}{lcccc}
\hline & \multicolumn{4}{c}{ Time 1 } \\
\cline { 2 - 5 } Time 2 & Intrusion & Avoidance & Hyperarousal & Total \\
\hline Intrusion & $.64^{* *}$ & .21 & $.50^{* *}$ & $.53^{* *}$ \\
Avoidance & .23 & $.52^{* *}$ & .29 & $.42^{*}$ \\
Hyperarousal & .23 & .33 & $.40^{*}$ & .37 \\
Total & $.46^{*}$ & $.46^{*}$ & $.48^{* *}$ & $.56^{* *}$ \\
\hline
\end{tabular}

$* p<.05$,

$* * p<.01, p<.001$

more Time 2 PTSD symptoms. When examining the PTSD clusters individually, we found the relationship of more religion words at Time 1 with Time 2 symptoms was robust across all Time 2 symptom domains (i.e. intrusion, avoidance, hyperarousal). In addition, use of more anxiety words was specifically related to lower intrusion and avoidance, and not hyperarousal. Use of more first-person singular pronouns at Time 1 predicted higher intrusion symptoms at Time 2. Use of more words indicative of cognitive mechanisms at Time 1 predicted higher hyperarousal symptoms at Time 2. In examining gender as a variable, some effects were only significant for women: for women, Time 1 anxiety words $(r=-.53, p=.03)$ and religion words $(r=.64, p=.005)$ predicted Time 2 PTSD symptoms, but Time 1 anxiety and religion words did not significantly predict Time 2 PTSD for men ( $r=-.31, p=.35$ and $r=.31, p=.34$, respectively).

What features of narratives written five months after 9/11 are related to PTSD assessed at that time? Partial correlations were used to examine which narrative characteristics at Time 1 predicted psychopathology at Time 2, with PTSD symptom level at Time 1 and each linguistic element entered as covariates (e.g. partial correlation of Time 2 PTSD symptoms and Time 2 pronouns, controlling for Time 1 PTSD symptoms and Time 1 pronouns). More Time 2 hyperarousal symptoms were significantly related to use of more words related to anger at Time 2. (Table 5.) Time 2 intrusion and

Table 4. Correlations between Time 1 linguistic elements and Time 2 PTSD symptoms, controlling for Time 1 PTSD symptoms

\begin{tabular}{|c|c|c|c|c|}
\hline $\begin{array}{l}\text { Linguistic } \\
\text { element }\end{array}$ & $\begin{array}{c}\text { T2 total } \\
\text { PTSD } \\
\text { symptoms }\end{array}$ & $\begin{array}{c}\mathrm{T} 2 \\
\text { Intrusion } \\
\text { symptoms }\end{array}$ & $\begin{array}{c}\mathrm{T} 2 \\
\text { Avoidance } \\
\text { symptoms }\end{array}$ & $\begin{array}{c}\mathrm{T} 2 \\
\text { Hyperarousal } \\
\text { symptoms }\end{array}$ \\
\hline $\begin{array}{l}\text { T1 Word } \\
\text { count }\end{array}$ & -.18 & .01 & -.21 & -.19 \\
\hline $\begin{array}{l}\text { T1 First- } \\
\text { person } \\
\text { singular }\end{array}$ & .28 & $.50 * *$ & .08 & .15 \\
\hline $\begin{array}{l}\text { T1 First- } \\
\text { person plural }\end{array}$ & .03 & .02 & .05 & -.05 \\
\hline T1 Anxiety & $-.43^{*}$ & $-.40^{*}$ & $-.37 *$ & -23 \\
\hline T1 Anger & .08 & -.21 & .15 & .24 \\
\hline $\begin{array}{l}\text { T1 Cognitive } \\
\text { mechanisms }\end{array}$ & .31 & .08 & .24 & $.43^{*}$ \\
\hline T1 Religious & $.65 * * *$ & $.67 * * *$ & $.44 *$ & $.47 *$ \\
\hline T1 Death & .37 & .27 & .34 & .24 \\
\hline
\end{tabular}


avoidance symptoms were not related to any linguistic elements of narratives at Time 2 when controlling for Time 1 linguistic elements and Time 1 PTSD. No gender differences emerged.

Which predictors of chronic PTSD are the strongest? A hierarchical regression was used to determine whether linguistic variables accounted for a significant amount of variance in Time 2 PTSD symptoms, and whether the addition of Time 1 PTSD symptoms contributed to the total variance accounted for in Time 2 PTSD symptoms. PTSD symptoms at Time 1 were entered in the first block; Time 1 linguistic variables were entered in the second block; Time 2 linguistic variables were entered in the third block (Table 6). When predicting overall Time 2 PTSD symptoms and all symptom clusters at Time 2, linguistic variables accounted for a significant amount of variance. Of note, while few individual linguistic variables were significant in the model, the overall model of linguistic variables predicted a significant amount of variance in Time 2 PTSD symptoms. Time 1 linguistic factors accounted for variance in Time 2 PTSD symptoms above and beyond Time 1 PTSD symptoms, and the addition of Time 2 narrative variables did not account for additional variance. No gender differences emerged.

\section{DISCUSSION}

\section{Summary of findings}

This study provides evidence that both acute and lasting PTSD symptoms can be indexed or predicted through linguistic indices sampled during the immediate aftermath of the trauma. Specifically, we find that acute PTSD symptoms are related to diminished use of first-person plural pronouns. In comparison, lasting PTSD symptoms are predicted by greater use of words related to religion, cognitive mechanisms, first-person singular pronouns, and by use of fewer anxiety-related words immediately following 9/11. Equally important, the inclusion of Time 1 linguistic variables in a regression model predicted sustained PTSD

Table 5. Correlations between Time 2 linguistic elements and Time 2 PTSD symptoms, controlling for Time 1 linguistic elements

\begin{tabular}{lcccc}
\hline Linguistic element & T2 Total PTSD symptoms & T2 Intrusion symptoms & T2 Avoidance symptoms & T2 Hyperarousal symptoms \\
\hline T2 First-person singular & .03 & .19 & -.08 & -.04 \\
T2 First-person plural & .09 & -.06 & -23 & -.03 \\
T2 Anxiety & -.03 & -.09 & .05 & -.05 \\
T2 Anger & .1 & -.05 & .04 & $.39 * *$ \\
T2 Cognitive mechanisms & -.05 & -.14 & -.01 & .04 \\
T2 Religious & -.13 & -.15 & -.05 & -.2 \\
T2 Death & -.12 & -.04 & & -.28 \\
\hline
\end{tabular}

$* p<.05 ;$ T2 $=$ Time 2

PTSD, Post-traumatic stress disorder.

Table 6. Variance accounted for in overall Time 2 PTSD symptoms by Time 1 linguistic variables, Time 2 linguistic variables, and overall Time 1 PTSD symptoms

\begin{tabular}{|c|c|c|c|c|c|c|c|}
\hline Model & Predictor & $B$ & $S E B$ & $\beta$ & $R$ & $R^{2}$ & $R^{2}$ Change \\
\hline 1 & Time 1 PTSD & .49 & .14 & $.56 * *$ & .56 & .31 & \\
\hline \multirow[t]{6}{*}{2} & Time 1 PTSD & .34 & .12 & $.41 * *$ & .85 & .73 & $.42 * * *$ \\
\hline & Time 1 First-person singular & .07 & .38 & .03 & & & \\
\hline & Time 1 First-person plural & -1.45 & .24 & -.08 & & & \\
\hline & Time 1 Anxiety & -5.59 & 2.58 & $-.28 *$ & & & \\
\hline & $\begin{array}{l}\text { Time } 1 \text { Cognitive } \\
\text { mechanisms }\end{array}$ & 2.38 & 1.00 & $.27 *$ & & & \\
\hline & Time 1 Religious & 2.99 & .88 & $.46^{* *}$ & & & \\
\hline \multirow[t]{12}{*}{3} & Time 1 PTSD & .43 & .11 & $.48 * *$ & .930 & .864 & .075 \\
\hline & Time 1 First-person singular & .06 & .43 & .02 & & & \\
\hline & Time 1 First-person plural & -2.33 & 2.20 & -.13 & & & \\
\hline & Time 1 Anxiety & -6.88 & 2.71 & $-.33 *$ & & & \\
\hline & $\begin{array}{l}\text { Time } 1 \text { Cognitive } \\
\text { mechanisms }\end{array}$ & 1.54 & 1.28 & .18 & & & \\
\hline & Time 1 Religious & 3.22 & 1.05 & $.49 * *$ & & & \\
\hline & Time 2 First-person singular & -.64 & .67 & -19 & & & \\
\hline & $\begin{array}{l}\text { Time } 2 \text { First-person } \\
\text { plural }\end{array}$ & 1.41 & 2.77 & .06 & & & \\
\hline & Time 2 Anxiety & 1.10 & 6.03 & .03 & & & \\
\hline & Time 2 Cognitive mechanisms & -1.08 & .83 & -.17 & & & \\
\hline & Time 2 Religious & 1.55 & 1.27 & .17 & & & \\
\hline & Time 2 Anger & 1.55 & 1.27 & $.17 *$ & & & \\
\hline
\end{tabular}

$* p<.05$

$* * p<.01$,

$* * * p<.001 ; \mathrm{T} 1=$ Time $1, \mathrm{~T} 2=$ Time 2

PTSD, Post-traumatic stress disorder. 
symptom severity, in excess of variance accounted for by early symptoms and Time 2 narrative elements. These data are discussed below.

\section{Interpretation of data}

In the immediate aftermath of the events of 9/11, only the use of plural pronouns (e.g. "we", "us") was correlated with the severity of acute PTSD symptoms reported within 1 week of 9/11 (i.e. "Time 1"). These data suggest that individuals who use more first-person plural pronouns may have more social support following a traumatic event. Social support is a known factor in buffering traumatic stress, and prior research suggests that large-scale traumatic events may facilitate social bonding in their immediate aftermath ( Mehl \& Pennebaker, 2003). Such bonding may facilitate protection in the face of imminent threat, reflecting an evolutionarily advantageous social process (Hesse \& Main, 2006). In the case of our data, people who referenced social behavior may have been buffered from the immediate effects of traumatic stress. Another interpretation of these findings is that people who are in a socially dominant role, as indicated by their use of second-person plural pronouns, may be at decreased risk for acute PTSD symptoms. However, because of the absence of data on social support in this sample, one cannot interpret with certainty that plural pronouns are related to social support, or that pronouns would better predict posttrauma resilience than a direct social support assessment.

Use of more first-person singular pronouns at Time 1 predicted greater Time 2 PTSD symptoms, specifically more intrusion symptoms. Higher first-person singular pronouns may indicate that one is self-focused, rather than seeking interaction with others. Prior research has indicated that use of first-person singular pronouns correlates positively with depression (Rude et al., 2004) and social submissiveness (Chung \& Pennebaker, 2007). Thus, first-person singular pronouns may be indicative of greater impairment of mental and social functioning.

In comparison, several linguistic features predicted sustained PTSD symptom severity reported 6 months after the events of 9/11 (i.e. “Time 2"). First, people who initially used fewer words related to anxiety reported greater severity of PTSD symptoms at Time 2. This finding indicates that the avoidance of discussing negative emotions may indicate increased risk for PTSD, and carries important implications for the intervention and recovery from trauma. Current approaches to treatment (e.g. Litz, 2004; Brewin \& Holmes, 2003) posit that addressing negative emotions following a trauma can reduce lasting symptoms through prohibiting avoidance. This finding also indicates that people who later develop PTSD symptoms do not discuss anxiety in their narrative recollections of the event, possibly due to numbing or disengagement from the event. Thus, the current data may reflect a persistent inability or unwillingness to address painful affect, which has been referred to as experiential avoidance (Hayes, Wilson, \& Gifford, 1996).

Second, individuals who reported greater use of words indicative of cognitive mechanisms at Time 1 had significantly greater hyperarousal symptoms at Time 2 . One interpretation is that increased use of cognition words may be indicative of one's attempts to process the influx of information presented in trauma, and causation words may indicate an "overload" of information that was difficult for the participant to rationalize. A complementary hypothesis is that instead of focusing on affective processing of traumatic events, individuals who use more cognition words may be ruminating on an intellectual understanding of the event. This interpretation complements the finding on the inverse relationship between early use of anxiety words and later PTSD symptoms, and supports information processing theories of PTSD that relate pathology to the extent to which traumarelated material has been adequately processed (e.g. consolidated, catalogued, and stored in memory; Rauch \& Foa, 2006). Helping people to shift their focus from cognitions about an event to their emotional reactions about an event may facilitate such adaptive.

The finding that use of more cognition words at Time 1 predicted Time 2 PTSD symptoms complements findings by Cohn et al., (2004), where cognition words used in online journals increased in entries written from before to after 9/ 11. Although Cohn et al. did not have mental health data related to changes in the journal entries, other studies (Boals \& Klein, 2005; Kross \& Ayduk, 2008) have reported that increased use of cognitive mechanism words following difficult emotional events was related to less distress. Perhaps, the apparent contradiction in these findings may be explained by the timing of the assessments. Boals and Klein's writing assessment was conducted up to 12 months after an upsetting event, whereas the first writing assessment in this study was conducted within a week of the event. One might suggest that use of more cognition words after one has had time to recover from an emotional shock may be healing, as opposed to in the immediate aftermath of an event, where it might reflect emotional distancing. These findings are consistent with hypotheses suggested by Tausczik and Pennebaker (2010).

The novel association between use of religion words and later PTSD symptoms merits comment. We included this category of words because the literature has suggested religion as both a protective factor and a risk factor in the development of PTSD (Gerber, Bolls, \& Schuettler, 2011; Ano \& Vasconcelles, 2005). The category of religious words is broad and includes both pan-religious words (e.g. faith, pray) and religion-specific words (e.g. Jesus, Islam). In order to clarify our findings, we reviewed the narratives for religious references. In early narratives, religious references were most frequently reflective of exclamations such as "Oh my God," rather than references to the religion of the attackers or to religious acts (e.g. praying for safety). In this context, one might interpret the statement "Oh my God" as reflecting shock and alarm, emotional responses that are consistent with the PTSD trauma exposure criterion of fear, helplessness, and horror.

It is notable that this sample differed from published norms from emotional-writing paradigms (on frequency of word usage in key categories). This sample used relatively fewer first-person plural words, anxiety words, and cognitive mechanism words, and relatively more anger and religion words. This finding may be due to the circumstances of testing: emotional writing paradigms are not necessarily conducted in the immediate aftermath of a potentially 
traumatic event. Therefore, these word rates might provide valuable information on how emotions are expressed while one is experiencing significant distress: namely, less focused on reflective processes, and more focused on affects such as anger.

Several interesting gender differences emerged. Time 1 PTSD symptoms and Time 1 anxiety and religion words were not related to Time 2 PTSD symptoms for men in particular. First-person singular pronouns and words reflecting cognitive mechanisms were, however, indicative of Time 2 PTSD symptoms for both genders. These findings may reflect gender differences in how distress is expressed: men may be less prone to use anxiety-related words regardless of their distress level. This finding suggests that in predominantly male samples commonly recruited for PTSD research, such as combat veterans, should take gendered expression of emotion into account when analyzing linguistic variables. However, given the small sample size, these findings should be taken as preliminary.

Finally, in contrast to Time 1 narrative elements, Time 2 narrative elements were less consistently related to Time 2 PTSD symptoms. Time 2 anger was related to Time 2 hyperarousal, which is consistent with the symptoms of this PTSD cluster, which includes anger and irritability as defining features.

Most important, early linguistic elements significantly accounted for the level of variance in sustained PTSD symptoms above and beyond the variance attributed to Time 2 narratives, and comparable with the variance contributed by Time 1 PTSD symptoms. This finding indicates that although self-reports of early PTSD symptoms predict sustained symptoms, other behavioral features, such as linguistic analyses, may be as valuable in symptom detection. Early symptom reports, particularly among people whose numbing symptoms, may under-emphasize client distress. These data indicate that individuals predisposed to sustained PTSD symptoms may under-report their initial distress, but their distress levels may be belied by their behavior or manner of speech when talking about a trauma. Alternatively, these data may indicate that narratives capture something meaningful in the process of sustained symptom development that may be captured by initial symptom self-report.

\section{Limitations and future directions}

This study is limited for the following ways. First, the participants are comprised of a small sample of undergraduate students, and may, thus, not be generalizable. However, it is of note that the participants are of a similar educational background, thus controlling for differences in intelligence or educational achievement. Second, because the participants reported relatively low levels of PTSD symptoms at Time 2, findings may not apply to people with clinicallysignificant PTSD. Third, because no control group was employed, it is impossible to discern whether the act of writing about a traumatic event enhanced or attenuated PTSD symptoms. It is important to note that the narrative prompt provided in this study was employed as a technique for assessing flashbulb memories, and not as an expressive writing intervention. Therefore, the findings in this study may not be comparable with other expressive writing intervention paradigms, but instead are more comparable with studies that analyze samples of text related to a particular topic, such as Cohn's analysis (2004) of online journal entries written before and after 9/11.

For more conclusive data, these findings should be replicated with larger, more diverse samples with clinicallysignificant PTSD symptoms. Pre-trauma narratives may also enhance these findings. Furthermore, it may be beneficial to examine how other trauma-related factors, such as peritraumatic distress, peritraumatic dissociation, and prior trauma history influence how narratives of trauma memories predict the development of PTSD symptoms.

\section{Conclusion}

These data indicate that features of PTSD may be detected through narratives written shortly after a trauma, indicating that such assessments may be useful in guiding post-disaster interventions. Although these data appear to suggest that engaging in the social and psychological processes indicated by the linguistic features of the narratives presented here (e.g. engaging affect, social support) may be in some way protective, these data are most pertinent for those interested in detecting persons at risk for chronic symptoms. Furthermore, these data contribute to a growing body of evidence that demonstrate that the linguistic analysis yields scientificallysignificant data and clinically-significant data that complement initial reports of PTSD symptoms.

\section{ACKNOWLEDGEMENTS}

The authors wish to thank all members of the Deldin Lab at Harvard University in the Fall of 2001 for assistance with data collection, and Brienne Brown for her assistance with manuscript preparation.

\section{REFERENCES}

Alvarez-Conrad, J., Zoellner, L. A., \& Foa, E. B. (2001). Linguistic predictors of trauma pathology and physical health. Applied Cognitive Psychology, 15(7), Special issue: Trauma, stress, and autobiographical memory, S159-S170.

Ano, G. G., \& Vasconcelles, E. B. (2005). Religious coping and psychological adjustment to stress: A meta-analysis. Journal of Clinical Psychology, 61(4), 461-480.

Blanchard, E. B., Rowell, D., \& Kuhn, E. (2005). Posttraumatic stress and depressive symptoms in a college population one year after the September 11 attacks: The effect of proximity. Behaviour Research and Therapy, 43(1), 143-150.

Boals, A., \& Klein, K. (2005). Word use in emotional narratives about failed romantic relationships and subsequent mental health. Journal of Language and Social Psychology, 24(3), 252-268.

Brewin, C. R. \& Holmes, E. A. (2003). Psychological theories of posttraumatic stress disorder. Clinical Psychology Review, 23(3), 339-376.

Cardenas, J., Williams, K., \& Wilson, J. P. (2003). PTSD, major depressive symptoms, and substance abuse following September 11, 2001, in a Midwestern University population. International Journal of Emergency Mental Health, 5(1), 15-28. 
Chung, C. K., \& Pennebaker, J. W. (2007). The psychological function of function words. In K. Fiedler (Ed.), Frontiers of social psychology. New York: Psychology Press.

Cohn, M. A., Mehl, M. R., \& Pennebaker, J. W. (2004). Linguistic markers of psychological change surrounding September 11, 2001. Psychological Science, 15(10), 687-693.

Creamer, M., Bell, R., \& Failla, S. (2003). Psychometric properties of the impact of events scale - revised. Behaviour Research and Therapy, 41(12), 1489-1496.

Fivush, R., Edwards, V. J., \& Mennuti-Wasbhurn, J. (2003). Narratives of 9/11: Relations among personal involvement, narrative content and memory of the emotional impact over time. Applied Cognitive Psychology, 17(9), 1099-1111.

Gerber, M. M., Boals, A., \& Schuettler, D.2011 The unique contribution of positive and negative religious coping to posttraumatic growth and PTSD. Psychology of Religion and Spirituality, doi: 10.1037/a0023016.

Gonzales, A. L., Hancock, J. T., \& Pennebaker, J. W. (2010). Language indicators of social dynamics in small groups. Communication Research, 37(1), 3-19.

Hayes, S. C., Wilson, K. G., \& Gifford, E. V. (1996). Experiential avoidance and behavioral disorders: A functional dimensional approach to diagnosis and treatment. Journal of Consulting and Clinical Psychology, 64(6), 1152-1168.

Hesse, E. \& Main, M. (2006). Frightened, threatening, and dissociative parental behavior in low-risk samples: Description, discussion, and interpretations. Development and Psychopathology, 18(2), 309-343.

Kross, E., \& Ayduk, O. (2008). Facilitating adaptive emotional analysis: Distinguishing distanced-analysis of depressive experiences from immersedanalysis and distraction. Personality and Social Psychology Bulletin, 34(7), 924-938.

Lee, C. H., \& Park, J. (2004). Differences in styles of writing about a tragic public event over time. Psychological Reports, 94(3,Pt1), 1058-1060.

Litz, B. T. (2004). Early intervention for trauma and traumatic loss. New York, NY, US: Guilford Press.

Mehl, M. R. \& Pennebaker, J. W. (2003). The social dynamics of a cultural upheaval: Social interactions surrounding September 11, 2001. Psychological Science, 14(6), 579-585.

Newman, M. L., Groom, C. J., Handelman, L. D., \& Pennebaker, J. W. (In Press). Discourse processes. Gender differences in language use: An analysis of 14,000 text samples.

Ozer, E. J., Best, S. R., Lipsey, T. L., \& Weiss, D. S. (2003). Predictors of posttraumatic stress disorder and symptoms in adults: A meta-analysis. Psychological Bulletin, 129(1), 52-73.

Pennebaker, J. W., \& Lay, T. C. (2002). Language use and personality during crises: Analyses of Mayor Rudolph Giuliani's press conferences. Journal of Research in Personality, 36(3), 271-282.

Pennebaker, J. W., Francis, M. E., \& Booth, R. J. (2001). Linguistic inquiry and word count (LIWC): LIWC2001. Mahwah, NJ: Erlbaum Publishers.

Rauch, S. \& Foa, E. (2006). Emotional processing theory (EPT) and exposure therapy for PTSD. Journal of Contemporary Psychotherapy, 36(2), 61-65.

Rude, S. S., Gortner, E. M., \& Pennebaker, J. W. (2004). Language use of depressed and depression-vulnerable college students. Cognition and Emotion, 18(8), 1121.

Schuster, M. A., Stein, B. D., \& Jaycox, L. H. (2001). A national survey of stress reactions after the September 11, 2001, terrorist attacks. The New England Journal of Medicine, 345(20), 1507-1512.

Sexton, J. B., \& Helmreich, R. L. (2000). Analyzing cockpit communications: The links between language, performance, error, and workload. Human Performance in Extreme Environments, 5(1), 63-68.

Simmons, R. A., Gordon, P. C., \& Chambliss, D. L. (2005). Pronouns in marital interaction. Psychological Science, 16(12), 932-936.

Stone, L. D., \& Pennebaker, J. W. (2002). Trauma in real time: Talking and avoiding online conversations about the death of Princess Diana. Basic and Applied Social Psychology, 24(3), 173-183.
Tausczik, Y. R. P., \& Pennebaker, J. W. (2010). The psychological meaning of words: LIWC and computerized text analysis methods. Journal of Language and Social Psychology, 29(1), 24-54.

Weiss, D. S., \& Marmar, C. R. (1996). The impact of event scale--revised. In J. P. Wilson T. M. Keane (Eds.), Assessing psychological trauma and PTSD. New York, NY, US: Guilford Press.

Wolf, M., Sedway, J., Bulik, C. M., \& Kordy, H. (2007). Linguistic analyses of natural written language: Unobtrusive assessment of cognitive style in eating disorders. International Journal of Eating Disorders, 40(8), 711.

\section{APPENDIX 1 SAMPLE NARRATIVES}

\section{SAMPLE 1}

I had an interview at the admission office Tuesday morning, at 10:00 AM. I arrived at about a quarter after 9:00AM. A man who held the door open for me looked shaken. When I entered the foyer, I saw that about ten people were standing around, watching the TV. NBC was showing a breaking news banner, and I saw smoke and flames coming from the skyscrapers. I asked an elderly woman next to me, what had happened and she said that two planes had flown into the world trade center. I watched for a few minutes, leaning in the main desk. I then walked quickly to the phones to tell my dad in (another country) to turn on the news. He had not heard about the second plane. My interviewer came out of her office, we talked about the attack, and proceeded with the interview upon returned to the foyer. I was told by the man who had first held the door for me, that the Pentagon had been hit too. I began to shake and I sat down on the couch with my head in my hands for about 5 minutes. I then phoned my roommates and walked back to the yard.

\section{SAMPLE 2}

I went to check my e-mail on Yahoo and saw on the headlines that a plane had hit the World Trade Center. I then rushed up to my friend's room to watch it on TV.

\section{SAMPLE 3}

I was asleep in my bed when I heard my phone ring. I heard my friend telling me to go turn on the television. I turned it on and I could only see black smoke so I asked her what was happening. Then she told me two planes had been crashed into the World Trade Center and at least one other had been hijacked. I kept saying oh my god, and my roommate came out - asking what? I told her what was happening and then I hung up with (name removed) and we both watched in disbelieve. We kept the television on as we were getting ready to go on a walk, and then right before we left, we saw that the Pentagon had been hit too. 